\title{
EVALUATING THE ROLE OF PINTEREST IN EDUCATION AND THE PROFESSION OF INTERIOR ARCHITECTURE
}

\author{
Shirin IZADPANAH \\ Asst. Prof. Dr., Antalya Bilim University, Faculty of Fine Arts and Architecture, Department of Interior Architecture and Environmental \\ Design, shirin.izadpanah@gmail.com, ORCID: https://orcid.org/0000-0001-8395-7155 \\ Izadpanah, Shirin. "Evaluating The Role of Pinterest in Education and The Profession of Interior Architecture". idil, 87 (2021 Kasım): s. 1559- \\ 1572. doi: 10.7816/idil-10-87-01
}

\begin{abstract}
The number of social media platforms that influence interior architects are increasing and Pinterest is one of these instruments. Parallel to the increased use of Pinterest among designers and students, there is concern about pros and cons of this platform for education and profession of interior architecture. This study aimed to understand if interior architecture instructors, students and professional are engaged with Pinterest and how they evaluate the role of this platform for the profession and education of interior architecture. Accordingly, this study offers a theoretical framework that would underline the opportunities and threats of using Pinterest as a designer. In this scope, data was collected from 225 students, 30 instructors and 50 interior architects. Comparing the findings showed that while most of the students and instructors find Pinterest useful for education of interior architecture, the number of interior architects who believed Pinterest presented disadvantages for the profession of interior architecture were higher that those who found Pinterest useful. Results claim that educating both students and instructors about the dynamic role of the social media in transferring the teaching materials, collaborative learning and efficient academic interaction could enhance the integration of online media development and education. Findings from this study contribute to the existing literature on the role of social media on design-oriented education and professions.
\end{abstract}

Keywords: Pinterest, interior architecture education, interior architecture profession, design, research 


\section{Introduction}

Today, social media has an influential role on design-oriented education and professions (MuñozAlcántara et al. 2015, Popescu, 2014, Cho et al. 2016). Pinterest is one of these platforms that offers social interaction through images and therefore it is used by designers and students majoring in design. Pinterest was launched in March 2010 as an online virtual scrapbook in the form of a social platform (Horwitz, 2013). According to sproutsocial, the number of Pinterest users is rising steadily and in March 2021, the platform reached 450 million active users which is more than Twitter and Snapchat. 85\% of Pinterest users prefer the mobile application and reports claim that in the United States, 50\% of users also frequently shop on Pinterest (West 2021). Since design is about collaboration, students majoring in design have recently started to benefit from the collaborative tools provided by social media (Balakrishnan 2017, Rossitto et al. 2014). Interior design students are considered to be one of the biggest users of social media. In a study by Cho \& Cho (2019), Pinterest is rated as the most popular social media platform among interior design students. The study claims that students used Pinterest mostly for research and then for sharing at a lesser degree. Students using Pinterest as a search tool overlaps with how the platform describes itself: "a visual discovery tool that you can use to find ideas for all your projects and interests (Pinterest, 2015, Scolere \& Humphreys, 2016)". Looking at images and collecting samples to build knowledge about the subject of a design is considered to be a fundamental component of the design development process (Lawson 2004), so the comprehensive visual repository of Pinterest attracts design students and novice designers. While some of academics, designers and researchers believe in the essential role of using precedent images in developing their design, there is still considerable criticism among the design circuit about the risk of social media like Pinterest causing an "originality paradox" in design (Cullinane 2013, Scolere \& Humphreys 2016). Parallel to the increased use of social media among designers and students, there is concern about social media ruining the creativity and originality of design. In her book 'Why Social Media is Ruining Your Life', Katherine Omerod (2018) discusses how people's obsessive interaction with ShareStream of social media has led to recreation of the same image and design over and over. According to Noam Hazan (2017), designers are inclined to check social media like Instagram and Pinterest for inspiration before even beginning the design, increasing the risk of a lack of creativity and originality. The same author refers to the risk of duplication of design instead of seeking originality as one of the cons of social media for the design society. There is no doubt the social media like Pinterest has its own pros and cons and it is with the help of research that the design society can learn about the advantages and disadvantages of using social media to establish strategies that will help students and amateur designers in particular to use social media more efficiently. While existing research explores general interaction with Pinterest (Gilbert, et al. 2013, Zarro \& Hall 2012, Linder, Snodgrass \& Kerne 2014, Scolere \& Humphreys 2016), there is a lack of information on how professions and educational programs like interior architecture use this platform and how aware they are of the advantages and disadvantages. Thus, this study focuses on a group of participants consisting of interior architects, interior architecture lecturers and students and interprets their evaluations of the role of Pinterest in education/practice of interior architecture. The aim of this research was to create a preliminary theory that will contribute to identifying the advantages and disadvantages of Pinterest for the education and practice of interior architecture. Accordingly, this study offers a theoretical framework that would underline the opportunities and threats of using Pinterest as a designer.

\section{Literature Review}

Pinterest is a free online platform that is seen as a visual discovery medium. As Hansen, Nowlan, and Winter (2012: 2) described "Pinterest functions as a digital pin board. It lets users post images and vide os from the internet either while viewing a website or by using a URL and add user-created photos, both of which are referred to as pinning”. Pinterest contains billions of images all uploaded, labelled, and tagged by users of the platform and accordingly user engagement is measured with the frequency of pinning and repining images (Wilson 2017, Scolere 2019). Pinterest has become an important platform in design society. Designers show interest in Pinterest for the following reasons: 
1) Creating communicative interaction between designers (Gibbs et al. 2015).

2) Circulating and marketing of products and service to potential clients/customers (Silverman 2013).

3) Collaboration between team members in a firm or office since they can share images that would contribute to a design project by pinning (Lynley 2018).

4) Building a network outside their design cycle (Ness 2021)

5) Self-presentation (especially in the case of amateur designers) through attractive and creative pin boards (Scolere \& Lee Humphreys 2016)

6) A visual resource for inspiration (Tran 2019)

Interior architects and interior designers are also considered as active users of Pinterest. Interior spaces are by far one of the most popular topics on Pinterest. While some designers see Pinterest as a blessing, some consider it is a curse. Bazilian (2019) discusses the opinions of various interior designers on Pinterest. According to Bazilian post, while one designer believes.

Pinterest has helped her understand what her clients like or seek, a nother designer refers to the risk of clients coming with visuals that do not fit their space or project at all. However, at the end of her post, Bazilian claims that regardless of positive and negative opinions, all of the designers agreed that Pinterest has become an undeniable part of their profession. The main potentials and handicaps of Pinterest will be discussed in this section.

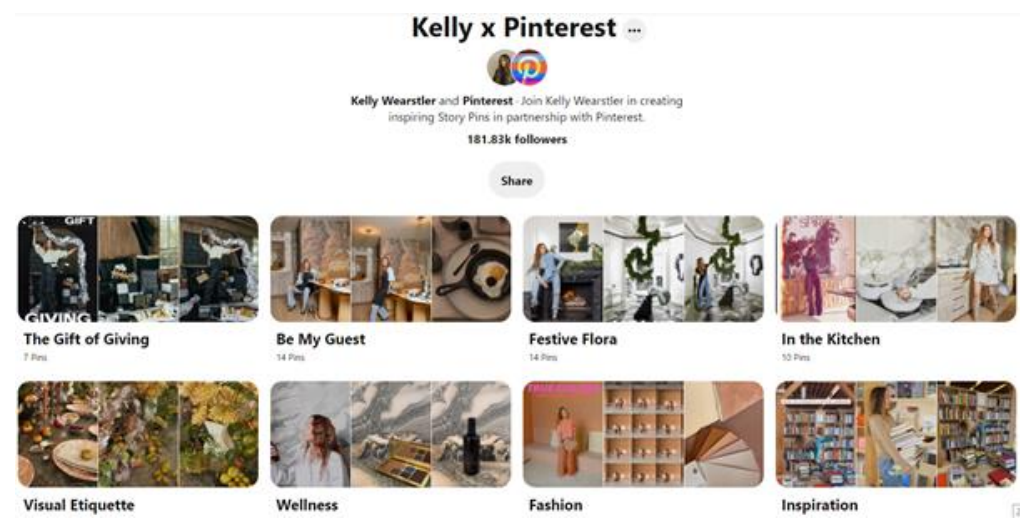

Figure 1. One of the famous interior designer accounts on Pinterest Kelly Wearstler's inspiring Story Pins in partnership with Pinterest (URL 1)

The second potential Pinterest provides for interior architects is e-marketing. Pinterest has started to use its platform for e-commerce to increase direct sales. It is discussed that pinning and re-pinning the same designs or styles can encourage users to purchase certain products (Linder et al. 2014, Hazari 2017). In line with this development, researchers suggest investigating the marketing potential of Pinterest to establish efficient marketing strategies (Hazari et al. 2017). Gayle Butler, editor in chief of the Better Homes and Gardens magazine, argues that Pinterest is an important platform for marketing visual brands, since the platform is "where images and ideas are so central (Cited in Miles \& Lacey 2013: p. 5)".

Using the right hashtags are now considered to be an essential strategy in Pinterest marketing. In 2017, Pinterest announced that they would allow using hashtags for 'categorising' and 'promoting' content. Using hashtags can help interior designers increase the awareness about their brand or service and also showcase their profile to potential consumers or clients (Lochery 2021). Hashtags mean categories and categories like Home Decor and Design Trending seem to be favorite hashtags on Pinterest, which make it easier for interior designers to reach their target audience (Agrawal 2016).

Another important Pinterest marketing strategy is to channel the right traffic to the designer or design 
firm profile, website and blog. Co-founder of NP Digital, Neil Patel (2021) recommends seven main tips that will increase account traffic. These are:

1) Use the Pinterest analytics feature and follow the strategies and contents that work the best

2) Use rich pins that sync information from your website to your Pins, so that if you change something in your website the rich pins will be updated to reflect the change

3) Follow and use the new tools that Pinterest updates exclusively for business accounts

4) Adding your different media like Instagram, Facebook, twitter and etc. links to your account

5) Sustain the popularity of your content by being aware popular pins, categories hashtags and creating visuals that work. Considering the optimal pin size matters in creating a potential visual

6) Optimize your pins to be seen and shared

7) Be active by posting frequently, commenting on followers' pins and following and engaging with popular boards

Infographics can be considered as another potential of Pinterest for interior architects (Doyle 2019, McCready 2017). According to Oxford English Dictionary, infographic is "a collection of imagery, charts, and minimal text that gives an easy-to-understand overview of a topic". Infographics generally can be classified as marketing infographics, educational infographics, event infographics, statistical infographics and business infographics (Nediger 2020). Since interior design is very much engaged with visual communication, creating and sharing creative infographics is one of the opportunities interior designers/architects can use to attract an audience on Pinterest.

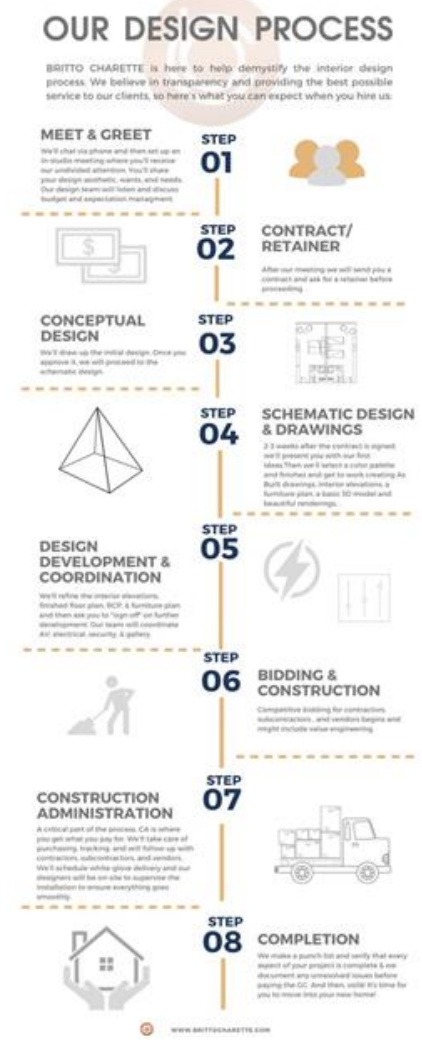

Figure 2. Infographic visual expressing the design service of Britto Charette Interior Design on Pinterest (URL 2)

Finally, Educational Content counts as another potential of using Pinterest. Pinterest is currently one of the popular social media tools in academia. Since the platform works like an online bulletin, teachers and 
students can exchange content by creating online boards (Thomas 2012). Studies claim that design students use Pinterest regularly. Design students mainly prefer to use Pinterest to upload, save, sort, and manage images. Another reason behind the rise in design students' interest in using Pinterest is looking for inspiration (Cho \& Cho 2019).

Julie DeNeen (2013) classified the advantages of Pinterest for educators and students which can also be applied for design students as follows:

1) Search tool: Pinterest allows users to access profiles that they are not connected with

2) Visual Tool: Rich visual archive of Pinterest enhances creativity and inspiration

3) Education Hub: Education counts as one of the largest categories of pins and boards

Literature still lacks adequate research on the disadvantages of Pinterest for designers and design education. But one of the main disadvantages of Pinterest for the design society seems to be an increase in imitations. Friz and Gehl (2016: p.9) suggest that Pinterest privileges "curation over creation" because sometimes the terms curation, meaning "re-pinning existing content on Pinterest", and creation, meaning creating something new and uploading, are confused.

Unfortunately, one of the realities with visual oriented platforms like Pinterest is that some of the designers copy and imitate existing designs instead of looking for inspiration, defeating the concept of originality and innovation in design. Copying and imitating designs disrespect the concept of originality and also increases the chances of a design lacking functionality and identity, because project development excludes any design process (Gholizadeh 2018).

Another disadvantage of Pinterest for designers is the risk of misinformation. Pinterest like any other social media platform presents the risk of spreading misinformation. Even though the website tries to fight with disinformation, this is challenging task and the problem of digital information pollution continues (Digital Learning \& Inquiry 2019). Relying mainly on images while lacking reliable technical and professional information carries a serious risk for students and amateur interior architects, because while visual images are central to their profession, designing an interior space requires sound technical information.

Another disadvantage of Pinterest presents for both interior architecture education and profession is the risk of killing creativity. Hazan (2017) emphasizes this risk by referring to "the beginning of the death of design". He goes further and claims that "true creativity is inspired by the surrounding environment, it is innovative, resourceful and most of all, it is original. But it is hard to think of something original when before beginning a design, one checks Pinterest for ideas and scrolls through an Instagram feed."

The same risk threats design education as well. Students can be too much into finding design ideas on Pinterest while forgetting to involve their own creativity. Filgo and Martinsen (2017) suggest including assignments and innovative instruction for interior design students on using Pinterest to encourage students to "see themselves as contributors to the information marketplace rather than only consumers of it". By gaining such skills, students will start to use the platforms like Pinterest efficiently and avoid being stuck in an infinite visual world that limits their creativity.

Studies also claim that professional designers prefer to use Pinterest for curating instead of creating content (Scolere \& Humphreys 2016). Popular interior designers like Kelly Wearstler, Alyssa Kapito, Amber Lewis etc. might have started to actively use their Pinterest profile, however there is still room for professional interior designer/architects to get greater exposure on Pinterest. This might direct students and amateur designers to reliable design resources rather than fake and unprofessional profiles.

Finally, another disadvantage of platforms like Pinterest is that it removes the distinction between amateur and professional designers (Bruns 2008, Perkel 2011). This is why designers complain about clients who come to them with visual boards that are completely irrelevant to their project. While some designers believe that Pinterest is democratizing design, some claim that everyone with a collection of visuals on Pinterest regards themselves a designer. This disadvantage, which is a struggle for some designers, is the ambiguity between the virtual world of Pinterest and reality (Bazilian 2019).

As discussed earlier, research on the disadvantages of Pinterest is very limited, and considering its increased popularity, there is a need to conduct further research that focuses on the pros and cons of this 
platform.

\section{Methodology}

To investigate the current perception towards using Pinterest in education and practice of interior architecture, this study brings together an analysis based on questionnaire data from three separate focus groups including interior architects, interior architecture instructors, and interior architecture students.

Each group was asked to answer questions that identify their personal use of Pinterest and define the advantages and disadvantages according to their experience. The focus groups were defined as follow:

- Students: 224 bachelor students from two universities in Antalya, Turkey studying interior architecture and interior architecture and environmental design.

- Design instructors: 30 instructors from 15 different universities who teach design courses in bachelor programs of interior architecture and interior architecture and environmental design.

- Interior architects: 50 professional interior architects mainly based in Antalya, Turkey.

The questionnaires were sent to students, instructors and interior architects via email. Participation was voluntary and a consent form providing the potential research subjects with sufficient information to decide whether to participate in this survey was sent in the same email. The total number of instructors in Antalya were limited therefore, a broader scope was employed for instructors in order to increase the number of participants.

Question topics for students included their personal use of Pinterest, the role of Pinterest in developing their design project, the disadvantages of using Pinterest and the use of other websites or applications in addition to Pinterest. Question topics for instructors included their personal use of Pinterest, the positive and negative roles of Pinterest in interior architecture education, their opinion on suggesting Pinterest to students and their thoughts on introducing a course in the interior architecture curriculum that focuses on the "efficient use of social media as a designer'. Lastly, question topics for interior architects included their personal use of Pinterest, the advantages and disadvantages of clients using of Pinterest and the role of Pinterest in the practice of interior architecture.

Multiple choice questions were analyzed by using the Excel programme and theme coding was employed to analyze the answers to the open-ended questions. Firstly, based on the main topics discussed in literature, an initial set of category codes including the pros and cons of social media use in design society were developed and participant answers were linked to corresponding codes. In the second step, new codes were developed for the answers which were not linked to any pre-defined codes. Refining the coding was continued in order to develop the categories presented in the findings.

Most of the students who took the course were in their first (8) and the second year (30) and only 4 out of 42 students were in their fourth year. Survey participation was on a voluntary basis and students were informed at the beginning of the semester that the results of the questionnaires would be used for research purposes. Students showed full participation in the questionnaire survey but since five students failed because of absence, the information was eventually obtained from 37 students.

\section{Findings}

In the first stage, data was collected from 225 interior architecture students. The questionnaire was sent to the interior architecture students in Antalya using Google forms. The aim of the study was explained in the email and it was emphasized that participation was voluntary. Findings from the student questionnaire revealed that $88 \%$ of students were using Pinterest and $79 \%$ of students had the Pinterest application installed on their devices (phone, computer, tablet, etc.). $76 \%$ of students claimed that Pinterest helped them during the development of their design project. Students using Pinterest to develop their project were also asked to explain how this application was helping them. This question was defined as an open-ended question. The analysis of students' answer is presented in chart 1. 


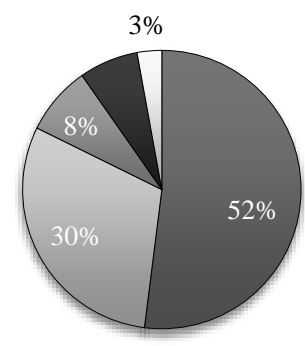

$\square$ To access a variety of samples
$\square$ To develop a concept/find
inspiration
$\square$ To develop the design process
$\square$ To improve my design
perception
$\square$ To help in design research

Chart 1. How students get help from Pinterest to develop their design project

Some of the students provided multiple reasons, but in general as presented in chart 1, most of the students were using Pinterest to find samples that help them develop their design. which was followed by finding inspiration.

Students were also asked if they relied on any other design website in addition to Pinterest. Only $42 \%$ of students answered yes to this question which demonstrated that most of the students only refer to Pinterest while looking for samples and inspiration. Finally, students were asked to share their thoughts on the disadvantages of using Pinterest. 73\% of students mentioned the disadvantage of using Pinterest and the analysis of their answers showed that the risk of copying and imitation (43\%) was the main disadvantage. $27 \%$ of participants did not mention any disadvantage (Chart 2).
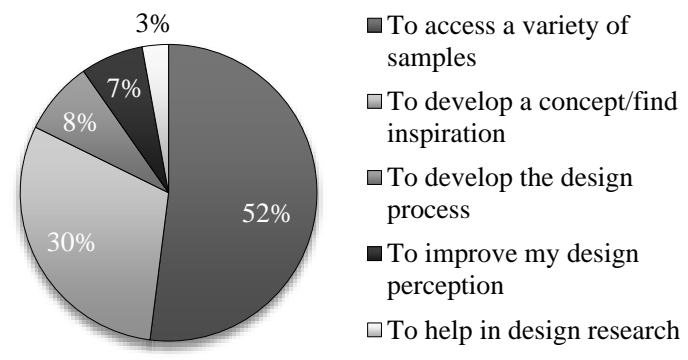

Chart 2. The disadvantages of using Pinterest in developing design projects according to students

In the second stage of data collection, an online questionnaire link was sent to 20 different interior architecture departments in Turkey and as a result, 30 interior architecture instructors agreed to participate in the survey. Findings demonstrated that $93 \%$ of instructors have the Pinterest application installed on their devices and use the application. $77 \%$ of instructors believed that using Pinterest was useful for students in interior architecture education. Instructors were then asked to explain their answer in an open-ended question. Similar to the findings from the student survey, accessing a variety of examples had the highest frequency as the main reason behind why instructors find Pinterest useful for students. Developing a better design perception and visual memory were the other reasons instructors believe Pinterest is useful in education.

On the other hand, providing incorrect and insufficient information, encouraging imitations, destroying creativity and originality were the reasons why instructors found Pinterest harmful in interior architecture education. Findings are presented in chart 3 and chart 4. 


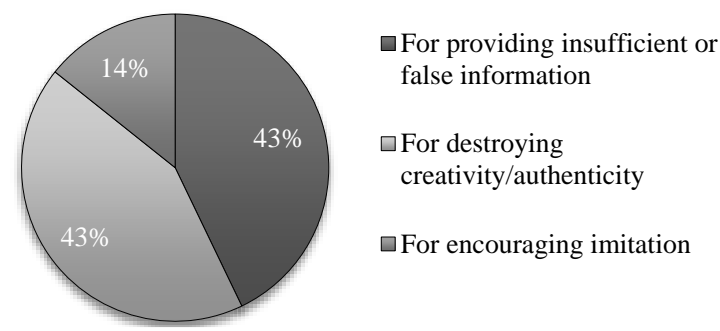

Chart 3. The reasons instructors find Pinterest harmful for interior architecture education

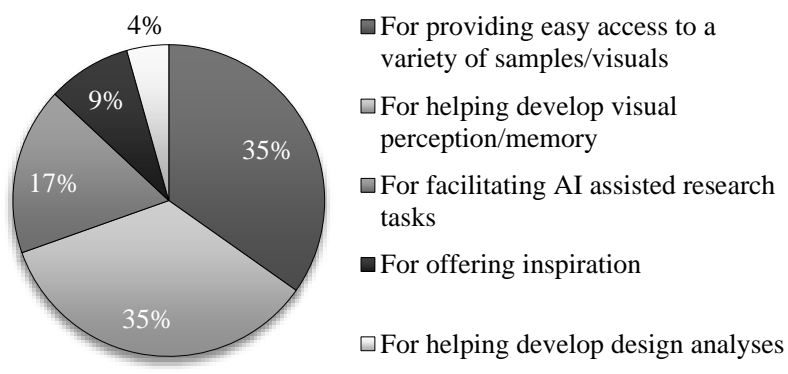

Chart 4. The reasons instructors find Pinterest useful for interior architecture education

Instructors were also asked if they recommended Pinterest to their students. Findings showed that $63 \%$ of instructors recommended using Pinterest to students. Instructors were then asked the reason behind recommending/not recommending Pinterest to their students. Some instructors gave more than one answer to this question. Findings from this question are presented in chart 5 and 6.

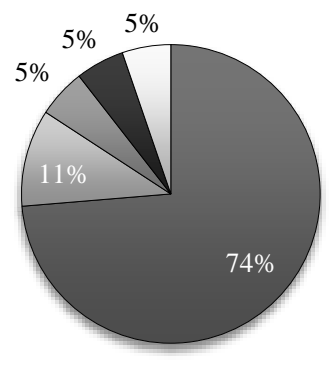

$\square$ For being inspirational

$\square$ For helping students develop their design perception/vision

$\square$ For helping students access a broad range of samples/visuals

$\square$ For helping students learn about composing designs

$\square$ For helping students develop visual memory

Chart 5. The reasons instructors recommend Pinterest to students 


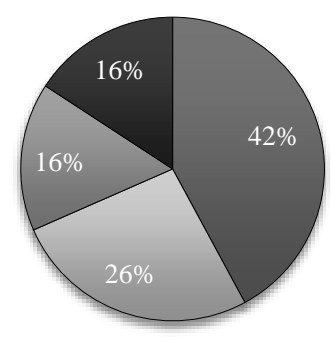

$\square$ For providing insufficient/false information

$\square$ For lacking technical specifications

$\square$ For limiting student creativity/authenticity

- For increasing the risk of copying designs

Chart 6. The reasons instructors do not recommend Pinterest to students

Finally, instructors were asked if they would consider including a course in the interior architecture curriculum that deals with research ethics and efficient social media use as a designer. Findings showed that $87 \%$ of instructors believed that it was unnecessary to include such a course in the program.

In the final stage of data collection, a questionnaire survey was shared with the members of Chamber of Interior Architecture in Antalya via email. 50 interior architects agreed to participate in the survey. Findings showed that $78 \%$ of interior architects use Pinterest and have the application installed on their devices. Interior architects were also asked if their clients were using Pinterest and $92 \%$ of interior architects answered yes to this question. Interior architects were then asked if they were happy that their clients were using Pinterest. The participants that answered yes to this question dropped to $46 \%$.

Interior architects were asked to explain why they were happy/unhappy with their clients using Pinterest. According to the findings, interior architects were unhappy with clients using Pinterest mainly because 'clients providing collections of samples put pressure on the designer which hinders creativity and authenticity'. On the other hand, interior architects were happy with their clients using Pinterest because the sample collection of clients gives them a better understanding of client expectations, tastes, and interests. Interior architects believed that this feature improved their communication with clients. Chart 7 and 8 present the analysis results from coding the reasons why interior architects were happy/unhappy with their clients using Pinterest.

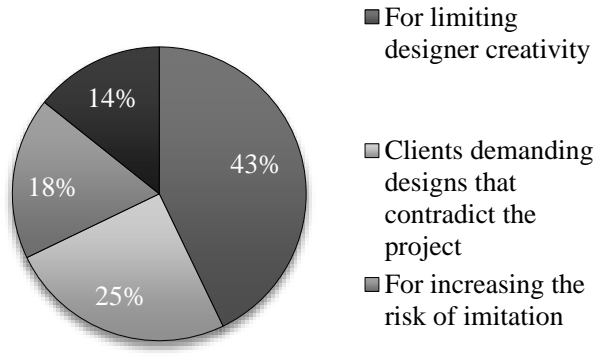

Chart 7. The reasons why interior architects are unhappy with their clients using Pinterest 


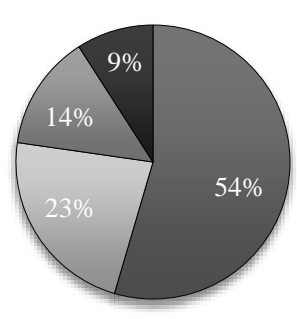

$\square$ For improving initial communication with the client

$\square$ For providing inspiration

$\square$ For improving the design vision of the client

— For helping clients

access contemporary

samples

Chart 8. The reasons why interior architects are happy with their clients using Pinterest

Interior architects were asked if they thought that Pinterest presented advantages for the profession of interior architecture. According to the findings, $36 \%$ of interior architects believed that the platform presents advantages while $38 \%$ believed that it presents disadvantages, and $26 \%$ believed that the platform presents both advantages and disadvantages. Finally, participants were asked to explain the reasons behind their answers. Findings showed that the main advantage for interior architects was the opportunity of seeing variety of designs. On the other hand, the main disadvantage for interior architects was the increased risk of imitation and similarity in design. Chart 9 and 10 present the analysis of the advantages and disadvantages suggested by interior architects.

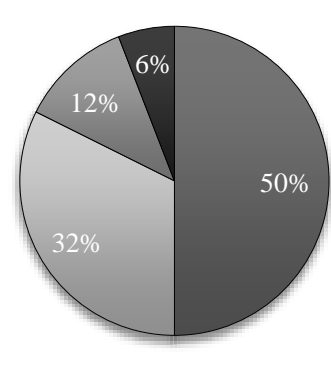

$\square$ For increasing the risk of imitations and similarities in design

$\square$ For ruining creative/original designs

$\square$ For straining client relations

—For lacking reliable/accurate information

Chart 9. The disadvantages of Pinterest according to interior architects

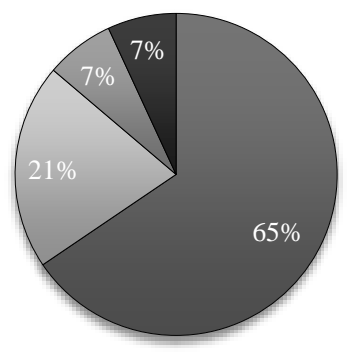

$\square$ For providing access to a variety of samples

$\square$ For keeping up-to-date with the developments

$\square$ For simplifying client communication

—For being a rich source of inspiration

Chart 10. The advantages of Pinterest according to interior architects 


\section{Conclusion}

The number of social media platforms that influence interior architects are increasing and Pinterest is one of these instruments currently gaining popularity in field of design. Since images play an influential role in inspiring interior architects and also finding samples related with design projects counts as an important part of preliminary design, Pinterest has found its way in to the profession and education of interior architecture. This study aimed to understand if interior architecture instructors, students and professional are engaged with Pinterest and how they evaluate the role of this platform for the profession and education of interior architecture. In this scope, data was collected from 225 students, 30 instructors and 50 interior architects. Overall, findings showed that a high percentage of participants in all three groups were using Pinterest and have the application installed on their devices.

Participants mainly referred to the advantages and disadvantages mentioned in literature, however some of the subjects noted in literature were not mentioned by participants. Existing theory and studies on the role of Pinterest on designs, designers and design education showed that this platform is a potential source for:

1) Visual search feature

2) Digital archiving of visuals and creating online pin boards

3) Source of inspiration

4) e-commerce and e-marketing that allows direct sales and leading potential customers to interior architects or firms

5) Share or learn from infographics

6) Exchange visual information between students and instructors

Findings from surveys also showed that the main advantage of Pinterest in interior architecture education according to students and instructors was the visual search feature and providing inspiration. Interior architects also regard the visual search feature as the main advantage of the platform.

Existing literature mainly refers to the increase in copying designs and imitations, the risk of misinformation, destroying creativity and originality and removing the barrier between amateur and professional designers as the main disadvantages of Pinterest for design-oriented professions like interior architecture. Findings from the current study shows that all three groups of participants mentioned the risk of increase in copy, imitations and similarity in design as the main disadvantage of using Pinterest. According to the results, destroying creativity and originality in design was the second main concern of participants using Pinterest. In line with literature, the instructors' main concern about Pinterest was the risk of misinformation. Interior architects also complained about clients finding samples that are irrelevant to their projects and expecting the designer to create the same design. This concern can also be discussed as a misinformation that images can provide for a person without inadequate design knowledge.

Comparing the findings showed that while most of the students and instructors find Pinterest useful for education of interior architecture, the number of interior architects who believed Pinterest presented disadvantages for the profession of interior architecture were higher that those who found Pinterest useful. Similarly, most interior architects were unhappy with their clients using Pinterest and complained that clients were coming with collections of samples that were irrelevant to the project and that this made it difficult for interior architects to convince their clients. Also, clients expecting design similar to their sample collections made it difficult for interior architects to employ their creativity. However, some interior architects found Pinterest useful because looking at clients' sample collection made it easier to communicate with their clients.

One of discussions in relation to the findings from current study is the need for introducing a course or teaching materials in the interior architecture curriculum that will help students learn about the efficient use of social media as a designer. While most of the instructors believed that there was no need to include such a course in the curriculum, findings showed that students, instructors and interior architects were not fully aware of the professional benefits of Pinterest. $62 \%$ of students mentioned that Pinterest was the only design website or application they use which shows how much students rely only on Pinterest for design research. Relying on one resource, which is mainly visual-based and lacking enough professional and technical information seems to be a serious concern. Such concerns raise the suspicions that educating students on the 
advantages, disadvantages and efficient use of social media might actually be necessary.

Studies confirm that social media can present huge potentials for collaborative learning and peer interaction. Such sophisticated technology-based communication is able to act revolutionary and offer drastic changes in higher education (Ansari \& Khan, 2020). Therefore, educating both students and instructors about the dynamic role of the social media in transferring the teaching materials, collaborative learning and efficient academic interaction could enhance the integration of online media development and education.

Findings from this study contribute to the existing literature on the role of social media on design-oriented education and professions. Considering the current role of Pinterest in education and the profession of interior architecture, findings from this research can be expanded by focusing on a larger number of participants for future studies. This research shows that there are insufficient studies on the advantages and disadvantages of Pinterest specifically for interior architecture, therefore more studies need to be carried out on this subject.

\section{Study Limitations}

This study explored the advantages and disadvantages of using Pinterest for education and the profession of interior architecture which mainly includes improved access to design samples, finding inspiration, the risk of increased imitations and similarities in design, the risk of ruining creativity and the impact of misinformation. The sample participants were bachelor students studying interior architecture, instructors in departments of interior architecture and interior architects mainly working in Antalya, Turkey. It would be interesting to study a larger group of academicians, students and professionals to see if the sample participants would provide the same results. Although the selection of questions in the surveys used in the current study were identified according to the data based on literature and modified for the context of the study, these questions might be insufficient due to the lack of adequate literature on the subject. Conducting further studies on Pinterest's role on the design society would contribute to the criteria excluded in the current study.

\section{References}

Agrawal, A. J. Social Media Marketing for Interior Designers -- How to Do It Right. Forbes. (2016, January 15). https://www.forbes.com/sites/ajagrawal/2016/01/15/social-media-marketing-for-interior-designers-how-to-do-itright/?sh=16ef13ee652f

Ansari, Jamal Abdul Nasir. \& Khan, Nawab Ali. "Exploring the role of social media in collaborative learning the new domain of learning". Smart Learning Environments, 7(1), 2020:1-16. doi:10.1186/s40561-020-00118-7

Balakrishnan, Vimala. "Key determinants for intention to use social media for learning in higher education institutions". Universal Access in the Information Society, 16(2), 2017: 89-301. DOI: org/10.1007/s10209-016-0457-0,

Bazilian, Emma. "Is Pinterest Ruining Interior Design-or Making It Even Better?”. House Beautiful. (2019, November 26). https://www.housebeautiful.com/design-inspiration/a29875495/pinterest-interior-design/.

Bruns, Axel. "Blogs, Wikipedia, second life, and beyond: from production to produsage". New York, NY: Peter Lang, 2008.

Cho, Ji Young., Cho, Moon-Heum. \& Kozinets Nadya. "Does the medium matter in collaboration? Using visually supported collaboration technology in an interior design studio". International Journal of Technology and Design Education, 26(4), 2015: 567-586.

Cullinane, Kate. "The original paradox. The Design Observer Group”. design observer. (2013, March 13). Retrieved from http://designobserver.com/feature/the-original-paradox/37733/

DeNeen, Julie. "Pinterest for Education: From Beginner to Advanced User". InformED. (2013, April 23). https://www.opencolleges.edu.au/informed/teacher-resources/pinterest-education/.

Digital Learning \& Inquiry. "Information environmentalism research: Fake accounts and mis/disinformation on Pinterest". Digital Learning \& Inquiry (DLINQ). (2019, October 23). https://dlinq.middcreate.net/digital-literacy/informationenvironmentalism-research-fake-accounts-and-mis-disinformation-on-pinterest/.

Doyle, Latasha. "How to Boost Your Pinterest Blog Traffic with Infographics". Social Media Marketing Tips and News. (2019, August 3). https://www.tailwindapp.com/blog/boost-pinterest-blog-traffic-infographics.

Filgo, Ellen. H. \& Martinsen, Megan. "Reframing Pinterest: Information Literacy for Interior Design Students", Internet Reference Services Quarterly, 22:2-3, 2017:107-121. DOI: 10.1080/10875301.2017.1373721 
Friz, Amanda. \& Gehl, Robert W. "Pinning the feminine user: Gender scripts in Pinterest's sign-up interface". Media, Culture and Society. Advance online publication. 38(5), 2016: 686-703. doi:10.1177/0163443715620925

Gholizadeh, Mahsa. "Design Inspiration Websites for Interior Designers: The Pros and Cons". LinkedIn. 2018, November 11. https://www.linkedin.com/pulse/design-inspiration-websites-interior-designers-pros-cons-gholizadeh/.

Gibbs, Martin., Meese, James,. Arnold, Michael., Nansen, Bjorn., \& Carter, Marcus, "Funeral and Instagram: Death, Social Media, and Platform Vernacular", Information, Communication \& Society, 18 (3): 2015: 255-268. doi:10.1080/1369118X.2014.987152.

Gilbert, Eric., Bakhshi, Saeideh., Chang, Shuo. \& Terveen, Loren G. "I need to try this? A statistical overview of Pinterest". In Proceedings of the SIGCHI conference on human factors in computing systems (pp. 2427-2436). New York, NY: ACM, 2013

Hansen, Kirsten., Nowlan, Gillian. \& Winter, Christina. "Pinterest as a tool: Applications in academic libraries and higher education". Partnership: The Canadian Journal of Library and Information Practice and Research, 7(2), 2012:1-11.

Hazan, Noam. "How Social Media Killed Creativity". LinkedIn. (2017, February 12). https://www.linkedin.com/pulse/howsocial-media-killed-creativity-noam-hazan.

Hazari, Sunil., Sethna, Beheruz N., Cheryl, O. \& Brown, Meara. "Determinants of Pinterest affinity for marketers using antecedents of user-platform fit, design, technology, and media content". International Journal of Technology Marketing, 12(3), 2017: 230-251. doi:10.1504/ijtmkt.2017.089646

Horwitz, Josh. "Semiocast: Pinterest now has 70 million users and is steadily gaining momentum outside the US". The next web. 2013. Retrieved from https://thenextweb.com/news/semiocast-pinterest-now-has-70-million-users-and-issteadily-gaining-momentum-outside-the-us

Lawson, Bryan. "What designers know". Amsterdam, The Netherlands: Architectural Press, 2004.

Linder, Rhema., Snodgrass, Clair. \& Kerne, Andruid. "Everyday ideation: All of my ideas are on Pinterest”. In Proceedings of the $32^{\text {nd }}$ annual ACM conference on Human factors in computing systems (pp. 2411-2420). New York, NY: ACM, 2014

Lochery, Kim. "The Definitive Guide to Pinterest Hashtags. Blogging Wizard”. (2021, March 27). https://bloggingwizard.com/pinterest-hashtags/.

Lynley, M. (2018, July 11). Pinterest is adding a way for users to collaborate on boards. TechCrunch. https://techcrunch.com/2018/07/11/pinterest-is-adding-a-way-for-users-to-collaborate-on-boards/.

McCready, Ryan. "6 Formulas for the Perfect Pinterest Infographic". Venngage. (2017, July 13).https://venngage.com/blog/6-formulas-for-the-perfect-pinterest-infographic/.

Miles, Jason., \& Lacey, Karen. "Pinterest power: market your business, sell your product, and build your brand on the world's hottest social network". McGraw-Hill: USA, 2013.

Alcántara, Jesús Muñoz., Markopoulos, Panos. \& Funk, Mathias. "Social media as ad hoc design collaboration tools". In: proceedings of the European conference on cognitive ergonomics 2015 (pp 1-8). Poland, 2015. https://doi.org/10.1145/27884 12.27884 20

Nediger, Midori. "What is an Infographic? Examples, Templates, Design Tips". Venngage. (2021, June 25). https://venngage.com/blog/what-is-an-infographic/.

Ness, Jonathan Van. "Pinterest launches Creator Code and new comment moderation tools to keep content positive, safe and inspiring". Pinterest Newsroom, (2021, April 7). https://newsroom.pinterest.com/en/creatorcode.

Ormerod, Katherine. "Why social media is ruining your life". UK: Hachette, 2018.

Patel, Neil. "How to Use a Business Pinterest Account for Marketing and Brand Growth". Nailpatel. (2021, February 11). https://neilpatel.com/blog/ultimate-pinterest-marketing-guide/.

Perkel. Daniel, "Making art, creating infrastructure: deviantART and the production of the web (PhD dissertation)". University of California Berkeley, 2011. Retrieved from http://www.escholarship. org/uc/item/6fg9f992

Pinterest. "About Pinterest". 2015. Retrieved from https://about.pinterest.com/en

Popescu, Elvira. "Providing collaborative learning support with social media in an integrated environment". World Wide Web, 17(2), 2012:199-212. doi:10.1007/s11280-012-0172-6

Rossitto, Chiara., Bogdan, Cristian. \& Severinson-Eklundh, Kerstin. "Understanding constellations of technologies in use in a collaborative nomadic setting". Comput Supported Coop Work, 23, 2014:137-161. https://doi.org/10.1007/s10606013-9196-4

Scolere, Leah. \& Humphreys, Lee. "Pinning Design: The Curatorial Labor of Creative Professionals". Social Media + Society, 2(1), 2016:1-13. doi:10.1177/2056305116633481

Silberman, Susan B. "Planning for the future". (2013, September 19). Retrieved from: http://blog.pinterest.com/post/61688351103/planning-for-the-future

Levy, Leah Anne. "Using Pinterest for Educational Purposes". TechSling Weblog. (2012, December 6). https://www.techsling.com/using-pinterest-for-educational-purposes/.

Tran, Tony Ho. "7 surprising sources of design inspiration: Inside Design Blog". invisionapp, inc. (2019, August 14). https://www.invisionapp.com/inside-design/design-inspiration/.

West, Chloe. "23 Pinterest stats and facts marketers must know in 2021”. Sprout Social. (2021, March 3). https://sproutsocial.com/insights/pinterest-statistics/ 
Wilson, Mark. "Pinterest Sees Its Future". Fast Company. (December 11. 2017). Retrieved from https://www.fastcompany.com/90152812/pinterest-sees-the-future

Zarro, Michael. \&, Hall, Catherine. "Pinterest: Social collecting for\# linking\# using\# sharing". In Proceedings of the 12th ACM/IEEE-CS joint conference on digital libraries (pp. 417-418). New York, NY: ACM, 2012. https://doi.org/10.1145/2232817.2232919

\section{References for Images}

URL 1: https://tr.pinterest.com/kellywearstler/kelly-x-pinterest/

URL 2: https://tr.pinterest.com/pin/534380312045980988/ 